\title{
Comunicación
}

\section{DERMATITIS ASOCIADAA Malassezia spp EN UN CONEJO (Oryctolagus cuniculus) CRIADO COMO MASCOTA}

\author{
Malassezia SpP Associated Dermatitis in a Pet Rabbit \\ (ORYCTOLAGUS CUNICULUS)
}

\author{
Miryam Quevedo U. ${ }^{1,3}$, Jesús Lescano G. ${ }^{1}$, Víctor Fernández A. ${ }^{2}$
}

\section{Resumen}

La enfermedad micótica más común en conejos es la dermatofitosis, la cual está asociada principalmente a Trichophyton menthagrophytes y Microsporum canis, mientras que la dermatitis por Malassezia spp ha sido raramente reportada en lagomorfos. El presente trabajo reporta el caso de un conejo Lop macho, de seis meses de edad que fue presentado a la consulta por un problema de dermatitis. El animal presentaba focos de alopecia, descamación de piel y fácil desprendimiento de pelo contiguo en tres áreas definidas. En el cultivo micológico en agar Saburaud glucosado a $25^{\circ} \mathrm{C}$ se llegó a aislar Malassezia spp. Se le hizo una terapia antifúngica con griseofulvina con resultados favorables, aunque llegó a hacer recidiva y fue tratado seguidamente con ketoconazol llegando a recuperarse de las lesiones de piel.

Palabras clave: lagomorfo, levadura, micosis cutánea, terapia antifúngica

\section{AbStract}

Dermatophytosis is the most common mycotic disease in rabbits which is mainly associated to Trichophyton menthagrophytes and Microsporum canis. On the other hand, dermatitis associated to Malassezia spp is rarely reported in lagomorphs. This paper describes a case of dermatitis in a Lop male rabbit of 6 months of age. The animal

\footnotetext{
${ }^{1}$ Laboratorio de Anatomía Animal y Fauna Silvestre, ${ }^{2}$ Clínica de Animales Menores, Facultad de Medicina Veterinaria, Universidad Nacional Mayor de San Marcos, Lima

${ }^{3}$ E-mail: mquevedo@veterinaria-unmsm.edu.pe
}

Recibido: 17 de febrero de 2013

Aceptado para publicación: 23 de mayo de 2013 
showed foci of alopecia, skin peeling and hair shedding in three defined areas. A skin sample was cultured in Sabouraud dextrose agar at $25^{\circ} \mathrm{C}$ and Malassezia spp was isolated. The animal received an antifungal therapy with griseofulvine obtaining favourable results; however, there was a recurrence and was treated with ketoconazole to fully recover from skin lesions.

Key words: lagomorph, yeast, cutaneous mycosis, antifungal therapy

\section{INTRODUCCIÓN}

La principal micosis en mamíferos pequeños mantenidos en cautiverio, como mascotas y animales de laboratorio, es la dermatofitosis. Esto no es un problema frecuente en conejos criados como mascotas ni en conejos silvestres; sin embargo, algunos individuos, posiblemente debido a un estado de inmunosupresión, pueden presentar este problema en forma esporádica. En animales inmunocompetentes, la piel intacta y la naturaleza fungistática del sebo (por su contenido de ácidos grasos) son una barrera eficaz contra la colonización micótica (Quinn et al., 2001; Lane, 2003; Marshall, 2003; Quesenberry y Carpenter, 2004; Percy y Barthold, 2007; van Praag, 2009).

La dermatofitosis es una micosis con potencial zoonótico causada por hongos queratinofílicos que infectan el estrato córneo de la piel, pelo y uñas. En conejos, los principales agentes causales son Trichophyton menthagrophytes $\mathrm{y}$ Microsporum canis, donde el primero puede estar presente de forma asintomática en el pelaje y el segundo proviene de contacto directo o indirecto con perros y gatos (Richardson, 2000; Rochete et al., 2003; Canny y Gamble, 2003; Quesenberry y Carpenter, 2004; Paterson, 2006).

El cuadro clínico se caracteriza por lesiones elevadas, circunscritas, eritematosas, cubiertas por descamación costrosa y frecuentemente pruriginosas; las cuales, aunque pueden presentarse en cualquier zona corpo- ral, generalmente inician su aparición en la cabeza (hocico y alrededor de los ojos y orejas), para avanzar hacia las patas (tiña pedis), uñas (onicomicosis) y espalda (tiña corporis) (Canny y Gamble, 2003; Rochette et al., 2003; Quesenberry y Carpenter, 2004; van Praag, 2009). Los conejos menores de seis meses de edad y los de avanzada edad son los grupos etarios más afectados (Canny y Gamble, 2003; Marshall, 2003; Quesenberry y Carpenter, 2004).

Entre los posibles diagnósticos diferenciales para dermatitis hiperqueratótica y alopecia en conejos se consideran la sarna psoróptica (Psoroptes cuniculi), sarna notoédrica (Notoedres cati), dermatitis por Cheyletiella y sarna sarcóptica (Sarcoptes scabiei). Además, recientemente se ha descrito la levadura Malassezia cuniculi sp. nov., aunque se dispone de pocos reportes de malasseziasis en lagomorfos y roedores (Radi, 2004; Cabañes et al., 2011).

\section{Caso Clínico}

\section{Historia Clínica}

En la Clínica de Animales Silvestres y Exóticos de la Facultad de Medicina Veterinaria (FMV) de la Universidad Nacional Mayor de San Marcos (UNMSM), Lima, Perú, se presenta a la consulta un conejo (Oryctolagus cuniculus) Lop macho, castrado, de 9 meses de edad, $1.76 \mathrm{~kg}$ de peso y 3.5 de condición corporal (en una escala de 1 


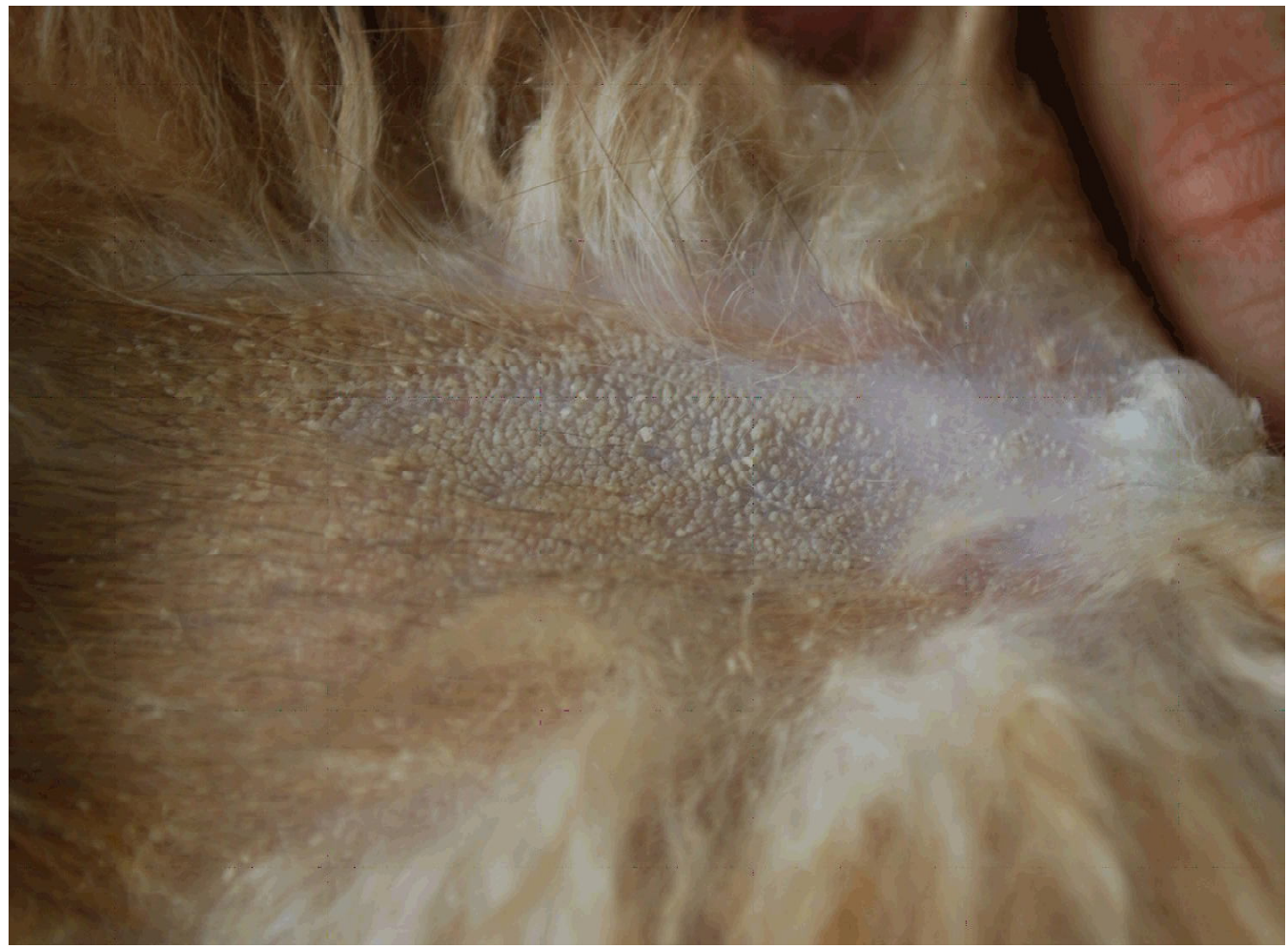

Figura 1. Lesión alopécica en un conejo Lop de seis meses de edad, con presencia de descamación de la piel y eritema en los bordes, correspondiente al día en que llegó a la consulta

a 5), que era criado como única mascota en una casa-departamento y alimentado con pienso concentrado. El animal presentaba pérdida de pelo en ambos flancos y alrededor del cuello, y prurito desde hace aproximadamente dos meses.

En ese periodo el conejo había recibido terapia parenteral con doramectina y terapia tópica con clorhexidina y una crema que contiene dexametasona, sulfato de neomicina, bacitracina, griseofulvina y benzocaína. Los propietarios manifestaron que la lesión en el cuello apareció luego que se le puso un collar isabelino como parte de la terapia recibida.

\section{Examen Clínico}

El paciente presentaba focos de alopecia, descamación de la piel y fácil desprendimiento de pelo contiguo en tres áreas defini- das: un foco severo a nivel cervical ventral $(4 \times 4 \mathrm{~cm})$, con edema y eritema en toda su superficie, extendiéndose alrededor del cuello con menor intensidad; un foco moderado a severo a nivel costo-abdominal derecho (16 $\mathrm{x} 6 \mathrm{~cm}$ ), con leve eritema en sus bordes; $\mathrm{y}$ un foco moderado a severo a nivel costo-abdominal izquierdo $(7 \times 5 \mathrm{~cm})$ con leve eritema en sus bordes (Fig. 1). En ninguna de las lesiones de piel se observó seborrea ni olor alguno en particular. Además, el paciente presentaba maloclusión, sobrecrecimiento de incisivos y sialorrea, que aparentemente humedecía el pelo del área mandibular ventral y cervical ventral.

\section{Exámenes Complementarios}

Se realizaron raspados de piel para descarte de presencia de ácaros mediante examen directo al microscopio y toma de mues- 


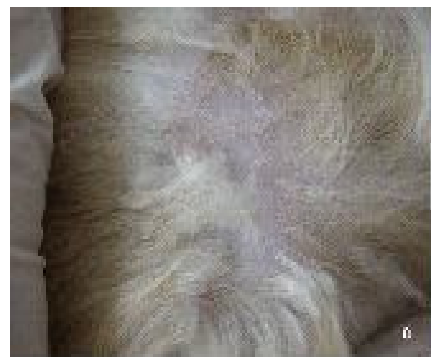

(a)

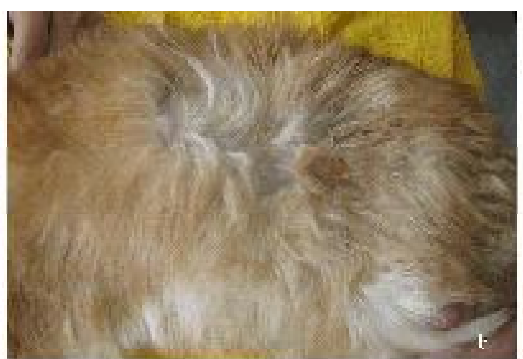

(b)



(c)

Figura 2. Evolución de las lesiones de piel en el día 14 de tratamiento. a) disminución de la descamación de piel. b) lesión en el lado izquierdo presentando mayor extensión. c) crecimiento de pelo en lesión en el área cervical

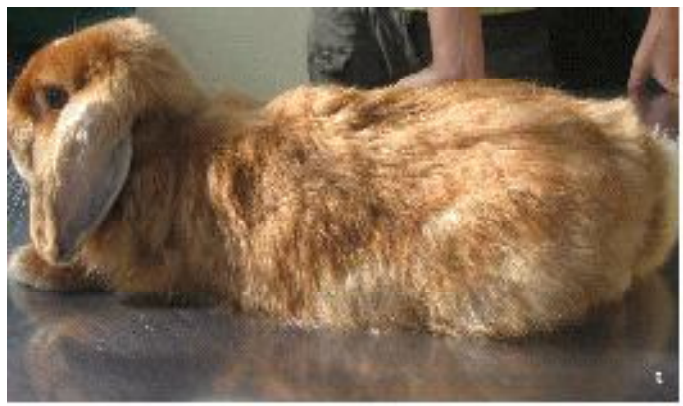

(a)

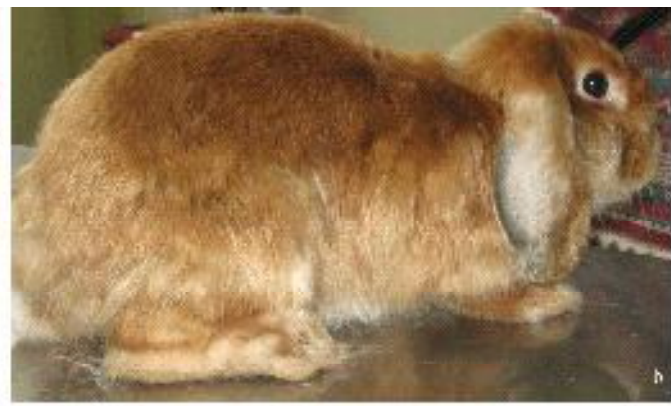

(b)

Figura 3. Recuperación total de las lesiones dérmicas al día 40 de tratamiento. a) flanco izquierdo. b) flanco derecho

tras de pelo para cultivo micológico en agar Saburaud glucosado a $25^{\circ} \mathrm{C}$ y tinción de las colonias con azul de metileno. De acuerdo a los resultados emitidos por el Laboratorio de Patología Clínica de la FMV-UNMSM, el raspado fue negativo a la presencia de ácaros y el cultivo micológico fue positivo a Malassezia spp.

\section{Diagnóstico, Tratamiento y Evolución}

Se diagnosticó dermatitis fúngica asociada a Malassezia spp en los flancos y cuello y dermatitis húmeda asociada a maloclusión de incisivos en área cervical ventral.
En espera de los resultados del cultivo micológico se administró clorfenamina a dosis de $0.3 \mathrm{mg} / \mathrm{kg}$, vía oral, cada 12 horas (Carpenter, 2005) y 10 días más tarde, habiéndose recibido el resultado micológico, se prescribió ketoconazol a dosis de $30 \mathrm{mg} / \mathrm{kg}$, vía oral, cada 24 horas (Rochette et al., 2003; Quesenberry y Carpenter, 2004; Carpenter, 2005; van Praag, 2009). Además, se practicó el recorte de dientes incisivos y se recomendó añadir vegetales a la dieta.

En el día 7 de tratamiento, las lesiones presentaban descamación y la lesión del lado izquierdo aumentó su extensión $(11$ x 6 cm). 
En el día 14 se observó mejoría en las lesiones de piel (Fig. 2), con inicio de crecimiento de pelo; sin embargo, solo la lesión del lado derecho redujo el área afectada $(3 \mathrm{x}$ $3 \mathrm{~cm}$ ), pues la del lado izquierdo se siguió expandiendo $(17 \times 7.5 \mathrm{~cm})$. Asimismo, los dueños manifestaron que el animal dejó de rascarse pero se lamía las lesiones.

En el día 21, la piel de los flancos no presentaba lesiones aparentes, y el área cervical ventral presentaba una pequeña zona de eritema $(1 \times 1 \mathrm{~cm})$. Se continuó el tratamiento por 14 días y el paciente se recuperó completamente de las lesiones de piel (Fig. 3). Sin embargo, los dueños indicaron que el animal seguía lamiéndose dichas áreas, por lo que se continuó el tratamiento con clorfenamina por siete días adicionales. El conejo se recuperó totalmente.

\section{Discusión}

Sobre la base del cultivo micológico se pudo realizar el diagnóstico de dermatitis asociada a Malassezia spp. Este patógeno ha sido reportado en la piel de especies vertebradas de sangre caliente como perro, gato, caballo, cabra, vaca, elefante, cerdo, mono, pelícano, ñandú y seres humanos, existiendo escasos reportes de esta levadura en conejos (Cabañes et al., 2011).

Para el diagnóstico de infecciones micóticas no es suficiente aislar el agente, sino demostrar el daño tisular que produce y descartar que sea un contaminante. Para este fin, se emplean pruebas como la tinción Gram, lámpara ultravioleta de Wood, citología, hidróxido de potasio, cultivo, serología y PCR, entre otras; sin embargo, la única prueba que determina la invasión micótica de un tejido es la histopatología (Lane, 2003). En el presente caso no se pudo realizar el examen histopatológico debido a que el propietario prefirió prescindir de dicha prueba y, consecuentemente, no se puede afirmar feha- cientemente que el agente aislado (Malassezia spp) sea el causante de las lesiones que presentó el paciente. Sin embargo, la respuesta favorable al tratamiento confirma indirectamente a la micosis como causa de la dermatitis.

A diferencia del aislamiento de Malassezia cuniculi sp. nov. realizado por Cabañes et al. (2011), donde la levadura no creció en agar Saburaud glucosado a $32{ }^{\circ} \mathrm{C}$, en el presente reporte Malassezia spp creció en este agar aunque a $25^{\circ} \mathrm{C}$, por lo que queda por dilucidar la especie a la que pertenece el agente aislado en este reporte.

La terapia antifúngica tópica empleada inicialmente contenía griseofulvina, un agente considerado efectivo contra todos los dermatofitos (Giguère et al., 2007; Maddison et al., 2008); sin embargo, dicho tratamiento no tuvo éxito posiblemente debido a que el agente causante de la enfermedad no pertenece a ese grupo de hongos ya que correspondía a una levadura (Malassezia spp) que no es afectada por dicho fármaco (Giguère et al., 2007). Por otro lado, la posterior terapia con ketoconazol tuvo éxito debido a que el espectro de esta droga, perteneciente al grupo de los derivados azoles, incluye a las levaduras (Giguère et al., 2007).

\section{Conclusiones}

Se reporta el primer caso de dermatitis asociado a Malassezia spp en conejos mascota en el Perú y su tratamiento efectivo empleando ketoconazol por vía parenteral.

\section{Literatura Citada}

1. Cabañes FJ, Vega S, Castella G. 2011. Malassezia cuniculi sp. nov., a novel species isolated from rabbit skin. Med Mycol 49: 40-48.

2. Canny CJ, Gamble CS. 2003. Fungal diseases of rabbits. Vet Clin Exot Anim 6: 429-433. 
3. Carpenter JW. 2005. Exotic animal formulary. $3^{\text {th }}$ ed. USA: Elsevier Saunders. 564 p.

4. Giguère S, Prescott JF, Baggot JD, Walker RD, Dowling PM. 2007. Antimicrobial therapy in veterinary medicine. $4^{\text {th }}$ ed. USA: Willey-Blackwell. $627 \mathrm{p}$.

5. Hartcourt-Brown F. 2002. Textbook of rabbit medicine. UK: ButterworthHeinemann. 410 p.

6. Lane RF. 2003. Diagnostic testing for fungal disease. Vet Clin Exot Anim 6: 301-314.

7. Maddison J, Page S, Church D. 2008. Small animal clinical pharmacology. $2^{\text {th }}$ ed. China: Saunders. 589 p.

8. Marshall KL. 2003. Fungal diseases in small mammals: therapeutic trends and zoonotic considerations. Vet Clin Exot Anim 6: 451-427.

9. Paterson S. 2006. Skin diseases of exotic pets. UK: Blackwell Science. 333 p.

10. Percy DH, Barthold SW. 2007. Pathology of laboratory rodents and rabbits. $3^{\text {th }}$ ed. USA; Blackwell Publishing. 325 p.
11. Quesenberry KE, Carpenter JW. 2004. Ferrets, rabbits and rodents: clinical medicine and surgery. $2^{\text {nd }} e d$. USA: Saunders. $197 \mathrm{p}$.

12. Quinn PJ, Markey BK, Carter ME, Donnelly WJ, Leonard FC. 2001.

Veterinary microbiology and microbial disease. UK: Blackwell Science. 536 p.

13. Radi ZA. 2004. Outbreak of Sarcoptic mange and malasseziasis in abbits (Oryctolagus cuniculus). Comparative Med 54: 434-437.

14. Richardson VCG. 2000. Rabbits health, husbandry and diseases. UK: Blackwell Sience. $178 \mathrm{p}$.

15. Rochette F, Engelen M, Vanden Bossche H. 2003. Antifungal agents of use in animal health - practical applications. J Vet Pharmacol Therap 26: 31-53.

16. van Praag E. 2009. Fungal dermatitis or superficial mycosis. [Internet]: Disponible en: http://www.medirabbit.com/ EN/Skin_diseases/Fungal/ Fungal_en.htm 